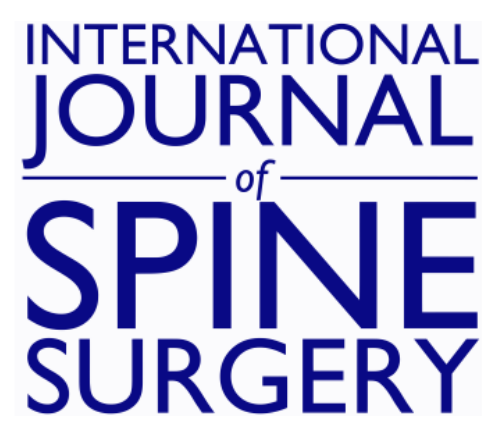

\title{
Current Concepts of Contemporary Expandable Lumbar Interbody Fusion Cage Designs, Part 2: Feasibility Assessment of an Endplate Conforming Bidirectional Expandable Interbody Cage
}

Boyle C. Cheng, Isaac Swink, Rachelle Yusufbekov, MICHELE Birgelen, Lisa Ferrara and Domagoj Coric

Int J Spine Surg 2020, 14 (s3) S68-S74

doi: https://doi.org/10.14444/7129

http://ijssurgery.com/content/14/s3/S68

This information is current as of April 26, 2023.

Email Alerts Receive free email-alerts when new articles cite this article. Sign up at: http://ijssurgery.com/alerts 


\title{
Current Concepts of Contemporary Expandable Lumbar Interbody Fusion Cage Designs, Part 2: Feasibility Assessment of an Endplate Conforming Bidirectional Expandable Interbody Cage
}

\author{
BOYLE C. CHENG, PHD,${ }^{1}$ ISAAC SWINK, MS, ${ }^{1}$ RACHELLE YUSUFBEKOV, $\mathrm{BS},{ }^{2}$ MICHELE BIRGELEN, \\ AS, ${ }^{1}$ LISA FERRARA, PHD ${ }^{3}$ DOMAGOJ CORIC, $\mathrm{MD}^{4,5}$ \\ ${ }^{I}$ Department of Neurosurgery, Allegheny Health Network, Pittsburgh, Pennsylvania, ${ }^{2}$ Integrity Implants, Inc, Palm Beach Gardens, Florida, ${ }^{3}$ OrthoKinetic \\ Technologies, LLC, Southport, North Carolina, ${ }^{4}$ Carolina Neurosurgery \& Spine Associates, Charlotte, North Carolina, ${ }^{5}$ Atrium Musculoskeletal Institute, \\ Charlotte, North Carolina
}

\begin{abstract}
Background: Expandable cages that allow for bidirectional expansion, in both height and width, may offer benefits over traditional expandable cages or static cages. Effective stiffness must also be considered, as implants with exceedingly high stiffness may increase subsidence risk and reduce graft loading.

Methods: A retrospective case series of 7 patients were assessed with computed tomography (CT) scan at the final 1-year follow-up to evaluate the interbody fusion and configuration of the expandable cage related to the endplates within the intervertebral space. CT scans were reformatted using cage's tantalum markers as fiducials for single-plane orientation for each intervertebral cage. Device height and width at maximum in situ expansion was measured at its anterior and posterior aspects to evaluate implant deformation. The new bone volume within each cage was measured from the same CT scan data sets and by the Bridwell classification of interbody fusion.

Results: The average difference between medial and lateral height measurements was $1.82 \mathrm{~mm}( \pm 1.08)$ at the device's anterior aspect and $1.41 \mathrm{~mm}( \pm 0.98)$ at the posterior aspect. The average difference between medial and lateral heights was $18.55 \%( \pm 9.34)$ anteriorly and $15.49 \%( \pm 9.24)$ posteriorly. There was a successful fusion in all 7 patients, as evidenced by measurable bone volume in the center of each interbody cage with an average of $586.42 \mathrm{~mm}^{3}( \pm 237.06)$.

Conclusion: The authors demonstrated the feasibility of successfully using bidirectionally expandable multimaterial cages to achieve interbody fusion. These composite open-architecture cages were found to conform to each patient's endplate configuration. The authors' observations support the concept of material selection impacting the effective construct stiffness. The design investigated by the authors provided sufficient anterior column support and successful fusion in all patients.
\end{abstract}

Level of Evidence: 4.

Special Issue

Keywords: computed tomography, fusion, interbody cages

\section{INTRODUCTION}

Newer expandable interbody cage designs incorporate combined components made of differing material, for example, titanium deposited onto a polyetheretherketone (PEEK) substrate. However, this design strategy's intent was focused on improving osseointegration rather than tailoring the construct stiffness. ${ }^{1}$ Many of the expandable interbody cages currently available rely on metallic materials incorporated into the expanding mechanism to facilitate expansion, resulting in construct stiffness similar to that of titanium and significantly higher than endplate stiffness. ${ }^{2,3}$ For those designs incorporating other polymer components, the polymer contributes to the effective stiffness depending on the configuration, with open geometries resulting in a reduced stiffness. As a result, these devices are likely to have construct stiffness dictated in part by the incorporated materials and device design. ${ }^{4-6}$

In this study, the authors investigated the feasibility of successful fusion with an endplateconforming interbody fusion cage (FlareHawk, Integrity Implants, Palm Beach Gardens, FL). Besides interbody fusion, the authors evaluated the implant's position and expansion in both width and 
height. The tested interbody device is a 2-piece device consisting of a PEEK shell that expands bidirectionally with the insertion of a titanium shim, thereby also restoring lordosis. The present study aimed to substantiate the concept of immediate anterior column support from the device's contribution to the instrumented functional spinal unit's (FSU) stability by leveraging polymers' material properties in combination with metal components in the implant design.

\section{MATERIALS AND METHODS}

\section{Patients and Study Design}

A retrospective case series of patients was evaluated at 1 year postoperatively from a posterior lumbar interbody fusion (PLIF) with a bidirectionally expandable interbody fusion cage and posterior supplemental fixation. All 7 patients were operated on by a single surgeon at a single site. All cases included in the series were 1- or 2-level PLIF constructs with 2 devices placed at each index level and supplemental fixation in the form of bilateral pedicle screws and rods. Institutional review board approval for this study was granted prior to study commencement by a centralized review board (Western Institutional Review Board; Puyallup, WA). Due to the retrospective nature of the study, a waiver for patient informed consent was provided.

\section{Radiographic Analysis}

Computed tomography (CT) scans were obtained from 7 patients to assess the interbody fusion and device deformation. DICOM data sets for each CT scan were imported to Mimics Medical, where dimensional measurements of device geometry and volumetric measurements of bone growth were performed. Device geometry was assessed in the coronal plane at both the anterior and posterior aspects of each device using the tantalum markers within the device as fiducial markers. Each device has 8 tantalum markers that were used to identify the corners of the PEEK support struts. To perform each measurement, the multiplanar reformatting (MPR) tool was used to align the scan such that the coronal plane bisects the 4 markers at either the anterior or posterior aspect of the device, as seen in Figure 1. The ellipse tool was used to find the center of each tag in a standardized manner. Measurement lines were then drawn from center to center point to measure the devices' height and width. Device height

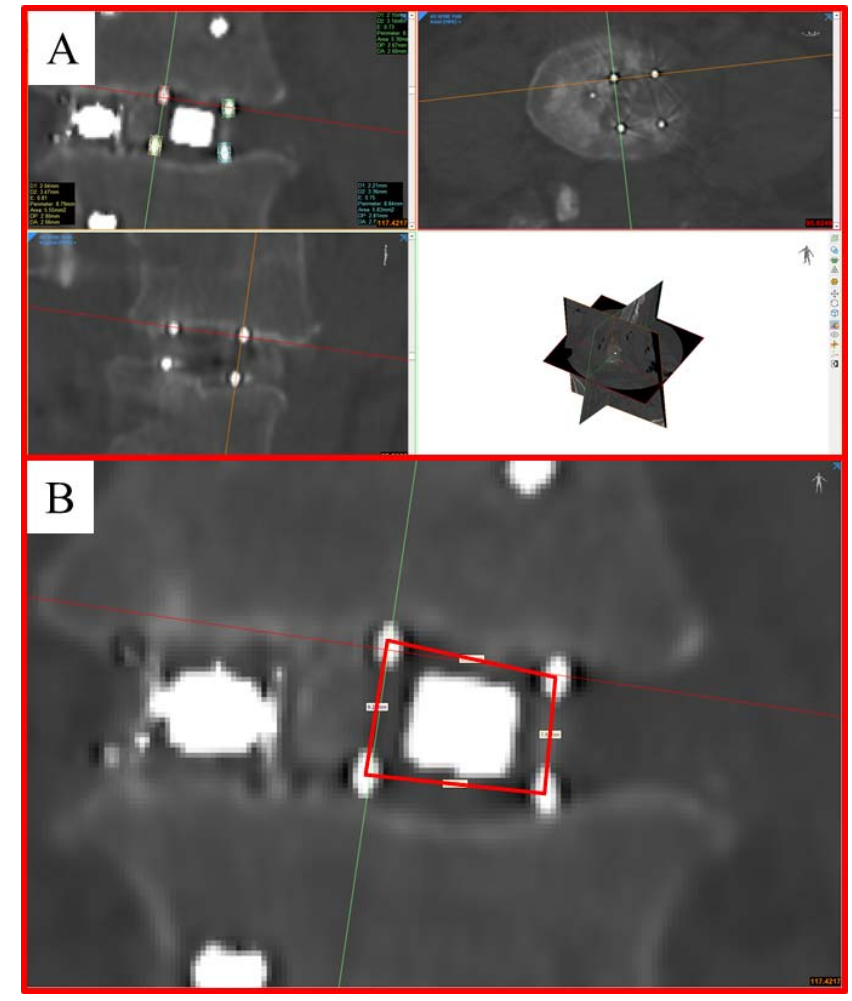

Figure 1. Illustration of procedure used to quantify implant deformation. (A) Alignment of coronal, axial, and sagittal planes according to the position of implant fiducials and creation of ellipses to find the center point of each marker. (B) Final placement of dimensional lines from which measurements were taken.

was then measured at both the medial and lateral aspects of each device. The width was measured at the superior and inferior aspects of the device. In total, 8 measurements were performed to assess the geometry of each device: anterior medial height $(\mathrm{AMH})$, anterior lateral height $(\mathrm{ALH})$, anterior width superior (AWS), anterior width inferior (AWI), posterior medial height $(\mathrm{AMH})$, posterior lateral height $(\mathrm{ALH})$, posterior width superior (AWS), and posterior width inferior (AWI). To determine if the device had deformed relative to its original geometry, these measurements were compared with an idealistic device geometry in which the device is ex vivo without loading or applied forces. In this ideal scenario, the dimensions of medial and lateral height and superior and inferior width would be identical; and any significant difference between sets of height and width measurements was considered evidence of deformation.

\section{Deformation and Fusion Analysis}

To determine if the observed deformation affected these 7 patients' fusion, volumetric measurements of bone growth within the graft window were also 


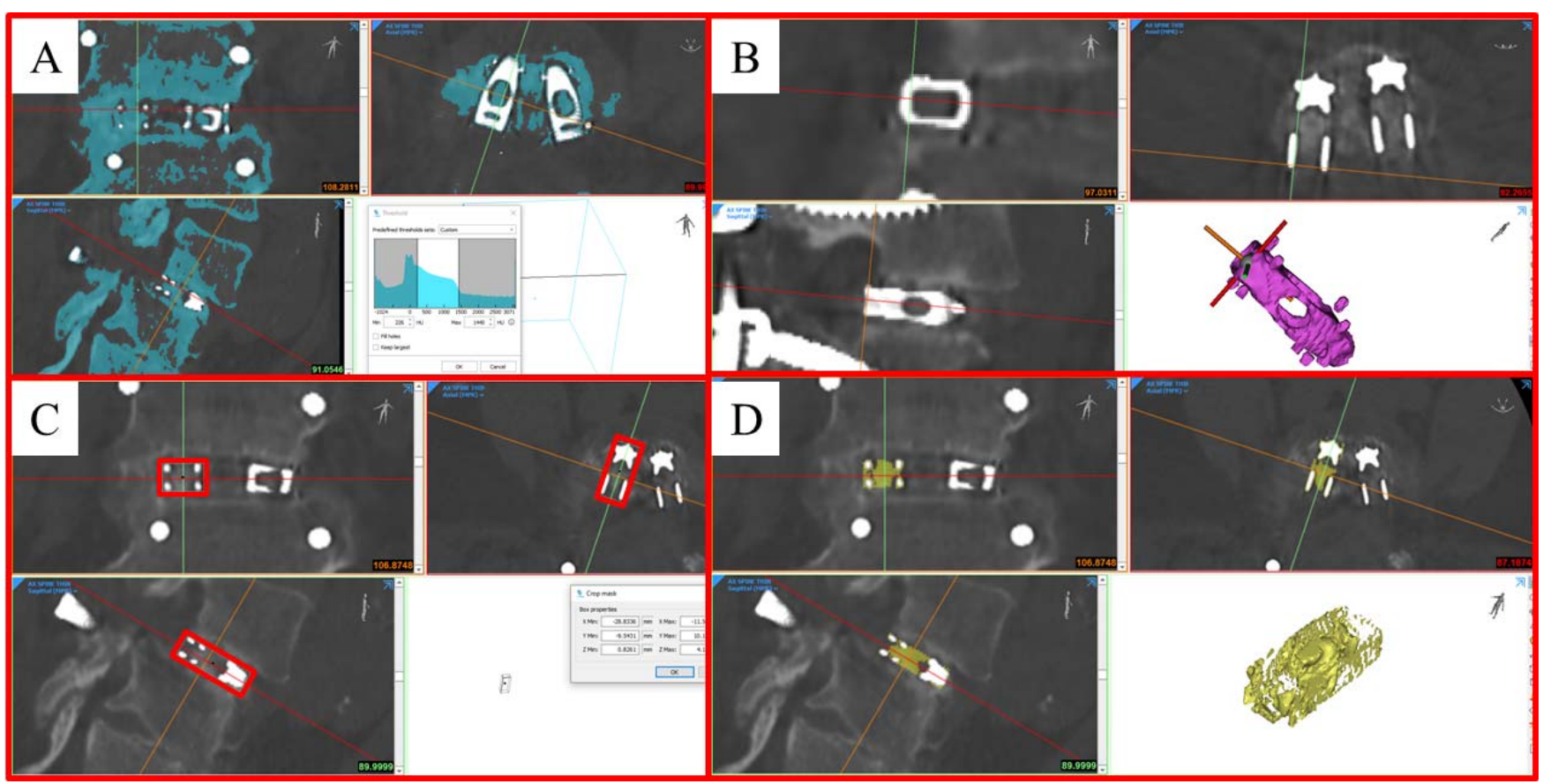

Figure 2. Illustration of procedure used to quantify bone within graft window. (A) Original mask is created to select all bone. (B) Multiplanar reformatting (MPR) is aligned to match the orientation of the titanium shim of each device. (C) Mask is cropped based on the maximum dimension of the titanium shim to produce volumetric data. (D) Final mask showing bone within graft window.

performed (Figure 2). The MPR tool was used to align the scan according to the titanium shim's orientation within each device, with the $\mathrm{x}-, \mathrm{y}-, \mathrm{z}$-axis of the shim being used to determine the direction of the coronal, axial, and sagittal planes. A region of interest (ROI) was then created surrounding the titanium shim such that the dimensions and orientation of the shim and ROI were identical. To quantify the bone volume present within this ROI, a segmentation mask was created based on the predefined bone CT thresholding window. The upper threshold was adjusted to remove all metal components and the same thresholding window being applied to all CT scans.

Table 1. Patient demographics.

\begin{tabular}{|c|c|c|c|}
\hline Patient & Sex & Age & Index Level \\
\hline 1 & F & 55 & L4-L5 \\
\hline 2 & F & 60 & L4-S1 \\
\hline 3 & F & 54 & L4-S1 \\
\hline 4 & M & 75 & L2-L3 \\
\hline 5 & M & 66 & L4-L5 \\
\hline 6 & M & 75 & L1-L2 \\
\hline 7 & M & 66 & L3-L4 \\
\hline
\end{tabular}

\section{RESULTS}

Patient demographic information can be found in Table 1. In total, 18 devices across 9 index levels were evaluated for deformation and bone volume present. A difference between medial and lateral height measurements was considered significant if the difference between measurements exceeded $10 \%$ of the largest value. As such, 16 of the possible 18 devices showed coronal plane deformation with variability between medial and lateral height measurements (Table 2). The average difference between medial and lateral height measurements was 1.82 $\mathrm{mm}( \pm 1.08)$ at the anterior aspect of the device and $1.41 \mathrm{~mm}( \pm 0.98)$ at the posterior aspect of the device. Hence, there was an average difference between medial and lateral heights of $18.55 \%$ $( \pm 9.34)$ anteriorly and $15.49 \%( \pm 9.24)$ posteriorly. In all but 2 cases, the medial height was larger than the lateral device height. Figure 3 illustrates mild, moderate, and pronounced implant deformation.

Regarding device-width, deformations were much less pronounced, with only 3 of 18 possible devices showing significant deformation (Table 3). The average difference between superior and inferior width measurements was $0.59 \pm 0.51 \mathrm{~mm}$ anteriorly and $0.58 \pm 0.54 \mathrm{~mm}$ posteriorly, which translates to differences of $4.72 \% \pm 4.07 \%$ and $4.68 \% \pm 4.35 \%$, 
Table 2. Deformation with respect to device height.

\begin{tabular}{|c|c|c|c|c|c|c|c|c|c|c|c|c|}
\hline \multirow[b]{2}{*}{ Patient } & \multirow{2}{*}{$\begin{array}{l}\text { Index } \\
\text { Level }\end{array}$} & \multirow[b]{2}{*}{ Side } & \multicolumn{2}{|c|}{ Evidence of Deformation $(\mathrm{Y} / \mathrm{N})$} & \multicolumn{4}{|c|}{ Anterior } & \multicolumn{4}{|c|}{ Posterior } \\
\hline & & & Anterior & Posterior & $\begin{array}{l}\text { Medial } \\
\text { Height } \\
(\mathrm{AMH})\end{array}$ & $\begin{array}{c}\text { Lateral } \\
\text { Height } \\
\text { (ALH) }\end{array}$ & $\begin{array}{c}\text { Height } \\
\text { Difference }\end{array}$ & $\begin{array}{c}\text { Height } \\
\text { Difference } \\
\text { (\% of } \\
\text { larger) }\end{array}$ & $\begin{array}{l}\text { Medial } \\
\text { Height } \\
(\mathrm{PMH})\end{array}$ & $\begin{array}{c}\text { Lateral } \\
\text { Height } \\
\text { (PLH) }\end{array}$ & $\begin{array}{c}\text { Height } \\
\text { Difference }\end{array}$ & $\begin{array}{c}\text { Height } \\
\text { Difference } \\
\text { (\% of } \\
\text { larger) }\end{array}$ \\
\hline 1 & L4-L5 & $\mathrm{L}$ & $Y$ & $\mathrm{~N}$ & 9.32 & 8.85 & 0.47 & 5.04 & 8.76 & 8.76 & 0 & 0 \\
\hline 1 & L4-L5 & $\mathrm{R}$ & $\mathrm{Y}$ & $Y$ & 9.96 & 7.16 & 2.8 & 28.11 & 8.75 & 6.56 & 2.19 & 25.03 \\
\hline 2 & L4-L5 & $\mathrm{L}$ & $Y$ & $Y$ & 9.94 & 7.14 & 2.8 & 28.17 & 8.41 & 6.87 & 1.54 & 18.31 \\
\hline 2 & L4-L5 & $\mathrm{R}$ & $Y$ & $Y$ & 9.23 & 7.97 & 1.26 & 13.65 & 7.35 & 6.13 & 1.22 & 16.60 \\
\hline 2 & L5-S1 & $\mathrm{L}$ & $Y$ & $Y$ & 9.04 & 8.22 & 0.82 & 9.07 & 6.94 & 6.24 & 0.7 & 10.09 \\
\hline 2 & L5-S1 & $\mathrm{R}$ & $Y$ & $Y$ & 9.01 & 7.82 & 1.19 & 13.21 & 7.29 & 7.09 & 0.2 & 2.74 \\
\hline 3 & L4-L5 & $\mathrm{L}$ & $Y$ & $Y$ & 12.83 & 9.81 & 3.02 & 23.54 & 10.79 & 7.81 & 2.98 & 27.62 \\
\hline 3 & L4-L5 & $\mathrm{R}$ & $Y$ & $Y$ & 12.66 & 8.62 & 4.04 & 31.91 & 10.9 & 7.26 & 3.64 & 33.39 \\
\hline 3 & L5-S1 & L & $Y$ & $Y$ & 10.04 & 8.33 & 1.71 & 17.03 & 8.12 & 7.37 & 0.75 & 9.24 \\
\hline 3 & L5-S1 & $\mathrm{R}$ & $Y$ & $Y$ & 10.05 & 6.82 & 3.23 & 32.14 & 9.13 & 7.6 & 1.53 & 16.76 \\
\hline$\overline{4}$ & L2-L3 & $\mathrm{L}$ & $Y$ & $Y$ & 6.37 & 5.12 & 1.25 & 19.62 & 10.26 & 8.5 & 1.76 & 17.15 \\
\hline$\overline{4}$ & L2-L3 & $\mathrm{R}$ & $Y$ & $Y$ & 6.29 & 9.1 & 2.81 & 30.88 & 6.22 & 8.26 & 2.04 & 24.70 \\
\hline 5 & L4-L5 & $\mathrm{L}$ & $Y$ & $Y$ & 8.1 & 5.93 & 2.17 & 26.79 & 9.37 & 8.13 & 1.24 & 13.23 \\
\hline 5 & L4-L5 & $\mathrm{R}$ & $\mathrm{N}$ & $\mathrm{N}$ & 8.17 & 8.25 & 0.08 & 0.97 & 8.33 & 7.86 & 0.47 & 5.64 \\
\hline 6 & L1-L2 & $\mathrm{L}$ & $\mathrm{Y}$ & $Y$ & 9.01 & 8.17 & 0.84 & 9.32 & 9.94 & 7.36 & 2.58 & 25.96 \\
\hline 6 & L1-L2 & $\mathrm{R}$ & $\mathrm{Y}$ & $\mathrm{Y}$ & 9.03 & 7.81 & 1.22 & 13.51 & 7.82 & 6.44 & 1.38 & 17.65 \\
\hline 7 & L3-L4 & $\mathrm{L}$ & $\mathrm{Y}$ & Y & 9.51 & 8.25 & 1.26 & 13.25 & 7.43 & 7.29 & 0.14 & 1.88 \\
\hline$\overline{7}$ & L3-L4 & $\mathrm{R}$ & $Y$ & $Y$ & 9.63 & 7.92 & 1.71 & 17.76 & 7.37 & 6.42 & 0.95 & 12.89 \\
\hline \multicolumn{5}{|c|}{ Average } & 9.34 & 7.85 & 1.82 & 18.55 & 8.51 & 7.33 & 1.41 & 15.49 \\
\hline \multicolumn{5}{|c|}{ Standard Deviation } & 1.61 & 1.08 & 1.05 & 9.34 & 1.31 & 0.77 & 0.98 & 9.24 \\
\hline
\end{tabular}

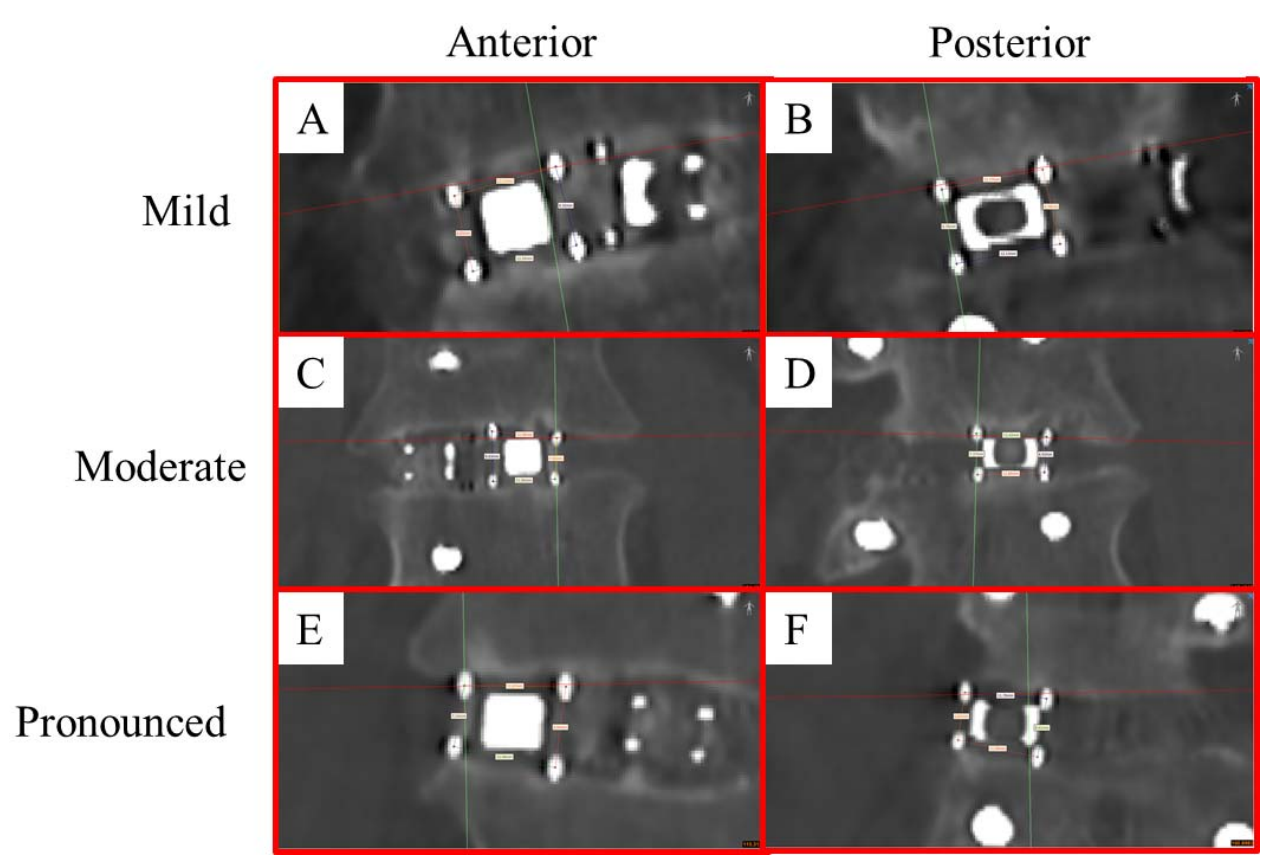

Figure 3. Representative examples of implant deformation showing mild (A, B), moderate (C, D), and pronounced (E, F) conformation to the disc space. (A, B) Anterior and posterior aspect of patient 1 left device showing $0.45-\mathrm{mm}$ and $0-\mathrm{mm}$ differences between medial and lateral height measurements. (C, D) Anterior and posterior aspect of patient 7 right device showing 1.71- $\mathrm{mm}$ and 0.75-mm differences between medial and lateral height measurements. (E, F) Anterior and posterior aspect of patient 2 left device showing 2.80- $\mathrm{mm}$ and 2.19-mm differences between medial and lateral height measurements. 
Table 3. Deformation with respect to device width.

\begin{tabular}{|c|c|c|c|c|c|c|c|c|c|c|c|c|}
\hline \multirow[b]{2}{*}{ Patient } & \multirow[b]{2}{*}{$\begin{array}{l}\text { Index } \\
\text { Level }\end{array}$} & \multirow[b]{2}{*}{ Side } & \multicolumn{2}{|c|}{$\begin{array}{c}\text { Evidence of } \\
\text { Deformation }(\mathrm{Y} / \mathrm{N})\end{array}$} & \multicolumn{4}{|c|}{ Anterior } & \multicolumn{4}{|c|}{ Posterior } \\
\hline & & & Anterior & Posterior & $\begin{array}{l}\text { Medial } \\
\text { Height } \\
\text { (AMH) }\end{array}$ & $\begin{array}{c}\text { Lateral } \\
\text { Height } \\
\text { (ALH) }\end{array}$ & $\begin{array}{c}\text { Height } \\
\text { Difference }\end{array}$ & $\begin{array}{c}\text { Height } \\
\text { Difference } \\
\text { (\% of } \\
\text { larger) }\end{array}$ & $\begin{array}{l}\text { Medial } \\
\text { Height } \\
\text { (PMH) }\end{array}$ & $\begin{array}{c}\text { Lateral } \\
\text { Height } \\
\text { (PLH) }\end{array}$ & $\begin{array}{c}\text { Height } \\
\text { Difference }\end{array}$ & $\begin{array}{c}\text { Height } \\
\text { Difference } \\
\text { (\% of } \\
\text { larger) }\end{array}$ \\
\hline 1 & L4-L5 & L & $\mathrm{N}$ & $\mathrm{N}$ & 12.13 & 12.24 & 0.11 & 0.90 & 11.77 & 12.13 & 0.36 & 2.97 \\
\hline 1 & L4-L5 & $\mathrm{R}$ & $\mathrm{N}$ & $\mathrm{N}$ & 12.06 & 12.63 & 0.57 & 4.51 & 11.68 & 12.77 & 1.09 & 8.54 \\
\hline 2 & L4-L5 & L & $\mathrm{N}$ & $\mathrm{N}$ & 11.87 & 12.08 & 0.21 & 1.74 & 11.7 & 11.59 & 0.11 & 0.94 \\
\hline 2 & L4-L5 & $\mathrm{R}$ & $\mathrm{N}$ & $\mathrm{N}$ & 11.9 & 12.45 & 0.55 & 4.42 & 11.63 & 12.18 & 0.55 & 4.52 \\
\hline 2 & L5-S1 & L & N & $\mathrm{N}$ & 12.17 & 12.13 & 0.04 & 0.33 & 11.94 & 11.93 & 0.01 & 0.08 \\
\hline 2 & L5-S1 & $\mathrm{R}$ & $\mathrm{N}$ & $\mathrm{N}$ & 12.18 & 12.15 & 0.03 & 0.25 & 12.04 & 12.08 & 0.04 & 0.33 \\
\hline 3 & L4-L5 & L & $\mathrm{N}$ & $\mathrm{N}$ & 11.98 & 11.89 & 0.09 & 0.75 & 11.79 & 11.87 & 0.08 & 0.67 \\
\hline 3 & L4-L5 & $\mathrm{R}$ & $\mathrm{N}$ & $\mathrm{N}$ & 12.45 & 11.33 & 1.12 & 9.00 & 12.38 & 11.76 & 0.62 & 5.01 \\
\hline 3 & L5-S1 & L & $\mathrm{N}$ & $\mathrm{N}$ & 12.51 & 11.84 & 0.67 & 5.36 & 12.23 & 12 & 0.23 & 1.88 \\
\hline 3 & L5-S1 & $\mathrm{R}$ & $Y$ & $Y$ & 13.04 & 11.35 & 1.69 & 12.96 & 12.79 & 11.3 & 1.49 & 11.65 \\
\hline 4 & L2-L3 & L & $Y$ & $Y$ & 11.18 & 9.94 & 1.24 & 11.09 & 12.03 & 10.07 & 1.96 & 16.29 \\
\hline 4 & L2-L3 & $\mathrm{R}$ & $Y$ & $Y$ & 10.91 & 12.5 & 1.59 & 12.72 & 11.18 & 12.53 & 1.35 & 10.77 \\
\hline 5 & L4-L5 & L & $\mathrm{N}$ & $\mathrm{N}$ & 12.43 & 11.96 & 0.47 & 3.78 & 12.36 & 11.87 & 0.49 & 3.96 \\
\hline 5 & L4-L5 & $\mathrm{R}$ & $\mathrm{N}$ & $\mathrm{N}$ & 11.81 & 11.79 & 0.02 & 0.17 & 11.02 & 11.34 & 0.32 & 2.82 \\
\hline 6 & L1-L2 & L & $\mathrm{N}$ & $\mathrm{N}$ & 12.3 & 12.63 & 0.33 & 2.61 & 12.32 & 11.75 & 0.57 & 4.63 \\
\hline 6 & L1-L2 & $\mathrm{R}$ & $\mathrm{N}$ & $\mathrm{N}$ & 12.7 & 12.04 & 0.66 & 5.20 & 12.2 & 12.01 & 0.19 & 1.56 \\
\hline 7 & L3-L4 & L & $\mathrm{N}$ & $\mathrm{N}$ & 11.85 & 12.3 & 0.45 & 3.66 & 11.7 & 11.91 & 0.21 & 1.76 \\
\hline 7 & L3-L4 & $\mathrm{R}$ & $\mathrm{N}$ & $\mathrm{N}$ & 12.59 & 11.9 & 0.69 & 5.48 & 12.62 & 11.89 & 0.73 & 5.78 \\
\hline \multicolumn{5}{|c|}{ Average } & 12.11 & 11.95 & 0.59 & 4.72 & 11.97 & 11.83 & 0.58 & 4.68 \\
\hline \multicolumn{5}{|c|}{ Standard Deviation } & 0.50 & 0.61 & 0.51 & 4.07 & 0.45 & 0.55 & 0.54 & 4.35 \\
\hline
\end{tabular}

respectively. Quantification of bone volume within each cage showed bone growth evidence into the center of all 18 devices (Table 4). The average bone volume within the titanium shim was $586.42 \pm$ $237.06 \mathrm{~mm}^{3}$.

\section{DISCUSSION}

This small case series demonstrates the feasibility of successful fusion with an endplate-conforming interbody fusion cage. The CT-image-based demonstration of cage deformation in all investigated planes provides a visual and numerical evidence of cage deformation in response to the patient's intervertebral space and endplate configuration. The present study also provides evidence in support of the observation that a bidirectional expandable interbody device supports fusion through a compliant shell that interfaces with the endplate and a titanium shim, which provides structural support. The results of the provided deformation analysis show that the final device geometry is a function not only of the device design but also conformation to each patient's unique disc space geometry. In those patients presenting with a "dome-like" anatomy, the device was sufficiently compliant to conform to the space. This is evidenced by the trend for device height measured in the medial aspect of the disc space to be consistently higher than the height measurements taken at the lateral aspect of the disc space. Furthermore, the average device deformation of $1.82 \mathrm{~mm}$ anteriorly and $1.41 \mathrm{~mm}$ posteriorly correlate well with values of endplate concavity depth reported in the literature, which range from 1.37 to $1.90 \mathrm{~mm}$ through the lumbar spine. ${ }^{11}$

The observed cage deformation serves to increase the surface area of the bone-implant interface and better distributes the load across the endplate. It also suggests that an interbody device with this unique combination of compliant and rigid components has the potential to conform to the interbody space while maintaining sufficient stability to achieve fusion. ${ }^{12,13}$ An implant with the ability to conform to the endplate represents a significant advancement, as Chatham et $\mathrm{al}^{14}$ showed that custom interbody devices can reduce stress at the bone-implant interface by up to $37 \%$ and rod stress by 28 . However, we cannot be certain this 
Table 4. Volumetric computed tomography measurements.

\begin{tabular}{|c|c|c|c|c|c|}
\hline Patient & $\begin{array}{c}\text { Index } \\
\text { Level }\end{array}$ & Side & $\begin{array}{c}\text { Lower } \\
\text { Threshold } \\
\text { (HU) }\end{array}$ & $\begin{array}{c}\text { Upper } \\
\text { Threshold } \\
\text { (HU) }\end{array}$ & $\begin{array}{c}\text { Shim BV } \\
\left(\mathrm{mm}^{\wedge} 3\right)\end{array}$ \\
\hline $\mathbf{1}$ & L4-L5 & R & 226 & 1440 & 464.57 \\
\hline $\mathbf{1}$ & L4-L5 & L & 226 & 1440 & 562.05 \\
\hline $\mathbf{2}$ & L4-L5 & R & 226 & 1440 & 509.79 \\
\hline 2 & L5-S1 & R & 226 & 1440 & 439.23 \\
\hline 2 & L4-L5 & L & 226 & 1440 & 607.32 \\
\hline 2 & L5-S1 & L & 226 & 1440 & 322.66 \\
\hline 3 & L4-L5 & R & 226 & 1440 & 525.13 \\
\hline 3 & L5-S1 & R & 226 & 1440 & 450.97 \\
\hline 3 & L4-L5 & L & 226 & 1440 & 313.93 \\
\hline 3 & L5-S1 & L & 226 & 1440 & 346.15 \\
\hline 4 & L2-L3 & R & 226 & 1440 & 819.60 \\
\hline 4 & L2-L3 & L & 226 & 1440 & $1,357.17$ \\
\hline 5 & L4-L5 & R & 226 & 1440 & 797.90 \\
\hline 5 & L4-L5 & L & 226 & 1440 & 762.55 \\
\hline 6 & L1-L2 & R & 226 & 1440 & 492.61 \\
\hline 6 & L1-L2 & L & 226 & 1440 & 545.87 \\
\hline 7 & L3-L4 & R & 226 & 1440 & 681.32 \\
\hline 7 & L3-L4 & L & 226 & 1440 & 556.64 \\
\hline & Average & & 226 & 1440 & 586.42 \\
\hline Standard Deviation & 0 & 0 & 237.06 \\
\hline & & & & & \\
\hline
\end{tabular}

deformation results in a significant increase in the surface area of the bone-implant interface due to the radiographic nature of the PEEK components.

Our study was limited by the small number of patients and short follow-up. As the number of devices featuring a combination of dissimilar materials and open geometries increases, the research surrounding how the construct stiffness of these devices influence arthrodesis with and without posterior supplemental pedicle screw fixation should also be studied. Ideally, the configuration would allow a compliant or less stiff shell to act as a cushion between a rigid inner core, much like the combination of PEEK and Titanium used in the FlareHawk design. The effective stiffness, or a combined spring effect between PEEK and titanium, has been shown to match with that of the FSU or bone more appropriately. Posterior element strain may also be reduced as long as the expandable device can maintain segmental stability. ${ }^{14}$

\section{CONCLUSIONS}

This feasibility study presents evidence that compliant expandable devices with the appropriate construct stiffness may provide the anterior column support necessary to facilitate arthrodesis. Although the potential to reduce device-related complications such as subsidence is theoretical at present, these potential clinically relevant attributes should be investigated to substantiate further the routine clinical use of bidirectional expandable multimaterial interbody fusion cages. The current study suggests that a device with construct stiffness more analogous to the bone may improve bone growth. The bidirectional expandable interbody device studied by the authors consistently conformed to the interbody space based on the differences between device height measured at the medial and lateral aspect of the disc space. The observed implant deformation did not appear to harm bone growth as volumetric analysis showed measurable bony formation in each device's center.

\section{REFERENCES}

1. Coric D, Branch CL. Posterior lumbar interbody fusion in the treatment of symptomatic spinal stenosis [published online ahead of print August 1997]. Neurosurgical Focus. 1997;3(2). doi:10.3171/foc.1997.3.2.11.

2. Ge DH, Stekas ND, Varlotta CG, et al. Comparative analysis of two transforaminal lumbar interbody fusion techniques: open TLIF versus Wiltse MIS TLIF. Spine (Phila Pa 1976). 2019;44(9):E555-E560. doi:10.1097/BRS. 0000000000002903

3. Zhao Y, Liang Y, Mao K. Radiographic and clinical outcomes following MIS-TLIF in patients with adult lumbar degenerative scoliosis. J Orthop Surg Res. 2018;13(1):93. doi:10. 1186/s13018-018-0764-7

4. Cao Y, Liu F, Wan S, et al. Biomechanical evaluation of different surgical procedures in single-level transforaminal lumbar interbody fusion in vitro. Clin Biomech (Bristol, Avon). 2017;49:91-95. doi:10.1016/j.clinbiomech.2017.08.011

5. Wilke HJ, Wenger K, Claes L. Testing criteria for spinal implants: recommendations for the standardization of in vitro stability testing of spinal implants. Eur Spine J. 1998;7(2):148154.

6. Newell N, Little JP, Christou A, Adams MA, Adam CJ, Masouros SD. Biomechanics of the human intervertebral disc: a review of testing techniques and results. $J$ Mech Behav Biomed Mater. 2017;69:420-434. doi:10.1016/j.jmbbm.2017.01.037

7. Bridwell KH, Lenke LG, McEnery KW, Baldus C, Blanke $\mathrm{K}$. Anterior fresh frozen structural allografts in the thoracic and lumbar spine. Do they work if combined with posterior fusion and instrumentation in adult patients with kyphosis or anterior column defects? Spine (Phila Pa 1976). 1995;20(12):1410-1418.

8. Fairbank J. Use of Oswestry Disability Index (ODI). Spine (Phila Pa 1976). 1995;20:1535-1537.

9. Fairbank JC, Pynsent PB. The Oswestry Disability Index. Spine (Phila Pa 1976). 2000;25:2940-2952; discussion 52.

10. Reed CC, Wolf WA, Cotton CC, et al. A visual analogue scale and a Likert scale are simple and responsive tools for assessing dysphagia in eosinophilic oesophagitis. Aliment Pharmacol Ther. 2017;45(11):1443-1448. 
11. $\mathrm{Xu} \mathrm{J,} \mathrm{He} \mathrm{Y,} \mathrm{Li} \mathrm{Y,} \mathrm{et} \mathrm{al.} \mathrm{Incidence} \mathrm{of} \mathrm{subsidence} \mathrm{of}$ seven intervertebral devices in anterior cervical discectomy and fusion: a network meta-analysis. World Neurosurg. 2020;141:479-489.e4. doi:10.1016/j.wneu.2020.03.130

12. Closkey RF, Parsons JR, Lee CK, Blacksin MF, Zimmerman MC. Mechanics of interbody spinal fusion. Analysis of critical bone graft area. Spine (Phila Pa 1976). 1993;18(8):10111015. doi:10.1097/00007632-199306150-00010

13. Cripton PA, Jain GM, Wittenberg RH, Nolte LP. Loadsharing characteristics of stabilized lumbar spine segments. Spine (Phila Pa 1976). 2000;25(2):170-179.

14. Chatham LS, Patel VV, Yakacki CM, Dana Carpenter R. Interbody spacer material properties and design conformity for reducing subsidence during lumbar interbody fusion. $J$ Biomech Eng. 2017;139(5):0510051-0510058. doi:10.1115/1. 4036312

Disclosures and COI: R. Yusufbekov is an employee of a device company; L. Ferrara received funding from a device company; D. Coric served as consultant and receives royalties from a device company. The other authors received no funding for this study and report no conflicts of interest.

Corresponding Author: Boyle Cheng, $\mathrm{PhD}$, 320 East North Ave, Suite 311, Pittsburgh, PA 15212. Phone: (412) 359-4020; Fax: (412) 359-4811; Email: boyle.cheng@ahn.org.

Published 9 December 2020

This manuscript is generously published free of charge by ISASS, the International Society for the Advancement of Spine Surgery. Copyright (C) 2020 ISASS. To see more or order reprints or permissions, see http://ijssurgery.com. 